\title{
Entre táticas e consumos de propostas curriculares no cotidiano escolar: um laboratório de química e uma sala de projetos
}

\section{Between tactics and consumptions of curricular proposals in daily school: a laboratory of chemistry and a room of projects}

Tacita Ansanello Ramos ${ }^{1}$. Maria Inês Petrucci-Rosa ${ }^{2}$

\begin{abstract}
Resumo: Pretende-se, neste artigo, focalizar como os praticantes do cotidiano consomem noções presentes nos documentos Parâmetros Curriculares Nacionais para o Ensino Médio (PCNEM) e Orientações Curriculares Nacionais para o Ensino Médio (OCNEM), e como tal prática se relaciona com a reconfiguração dos lugares da química dentro de uma instituição de ensino. Com base na pesquisa realizada, vem-se percebendo a substituição de lugares, em algumas instituições escolares, simbolicamente relacionados com a Química, assim como acervos de objetos relacionados com essas práticas disciplinares que vêm sendo ressignificados nos currículos praticados. Para compor o material empírico da pesquisa, foram desenvolvidos procedimentos de construção de dados com abordagem etnográfica e escuta de narrativas, incluindo registros fotográficos. Os discursos presentes nos PCNEM e OCNEM a favor da integração por áreas e do trabalho interdisciplinar, de certa forma, provocam efeitos nas práticas curriculares que vão reconfigurando o lugar para essa disciplina dentro de algumas instituições de ensino.
\end{abstract}

Palavras-chave: Ensino de química. Currículo. Ensino Médio. Política educacional.

\begin{abstract}
It is intended in this article focus on how the practitioners deal with notions in National Curricular Parameters for the High School (PCNEM) and the National Curricular Orientations for the High School (OCNEM) documents and how this is related to the reconfiguration of the place of chemistry within an educational institution. Based on a survey, we realized that the replacement of places in educational establishments symbolically related to the chemical as well as collections of objects related to these subject practices that is being resignified from curricular practices. To compose the empirical material, procedures have been developed to build data with an ethnographic approach and listening to narratives, including photographic records. Discourses present in PCNEM and OCNEM for the integration of areas and interdisciplinary work, in a way, cause effects on curriculum practices that reconfigures the place for that subject within some institutions of education.
\end{abstract}

Keywords: Chemistry teaching. Curriculum. High school. Educational policy.

\footnotetext{
${ }^{1}$ Rede Pública de Ensino do Estado de São Paulo, Avenida João Scarparo Netto, 240, ap. 13, Trovadores, Santa Genebra, CEP 13080-655, Campinas, SP, Brasil. E-mail: tacita_ramos@yahoo.com.br

${ }^{2}$ Departamento de Ensino e Práticas Culturais, Faculdade de Educação, Universidade Estadual de Campinas (Unicamp), Campinas, SP, Brasil.
} 


\section{Cotidiano e currículo: entre táticas na cultura escolar}

A diversidade e complexidade do cotidiano e da vida cotidiana, trespassada por relações sociais e práticas culturais que se cruzam e entrelaçam, precisam ser estudadas sempre levando em consideração sua multiplicidade. O estudo do cotidiano, como Certeau (1994) relata, consiste em abdicar da posição do olho que tudo vê, isto é, deixar de lado homogeneizações, por meio de um olhar atento para as particularidades, sem deixar de relacioná-las com as macroestruturas.

$\mathrm{Na}$ vida cotidiana, os usos que os indivíduos sociais fazem de certas situações, tornam-se relevantes quando assumimos esses usos como táticas exercidas pelos mesmos como formas de ressignificações e reinterpretações que, diariamente, são engendradas perante as estratégias as quais estão supostamente submetidos.

Sendo assim, o cotidiano passa a ser pensando como constante produção e criação que diariamente acontece, mesmo que sob uma determinada rotina.

No que concerne às instituições de ensino, pensar o cotidiano escolar é pensá-lo como espaço prenhe de jogos realizados pelos praticantes que nele estão inseridos, para os quais são dados lances proporcionais às situações. Cabe aos praticantes ordinários da vida cotidiana (CERTEAU, 1994) escolher a que lance recorrer em cada ocasião, praticantes esses que se servindo de táticas não enxergam o jogo em sua totalidade, mas transformam o cotidiano por meio do consumo ativo, utilizando suas maneiras de fazer (CERTEAU, 1994).

Pensar no cotidiano escolar é rapidamente relacioná-lo a algo que, diariamente, é motivo de disputas e embates nesse contexto: o currículo.

O estudo do campo do currículo é algo extremamente complexo já que a própria definição do termo se coloca como um desafio para aqueles que buscam compreendê-lo, uma vez que exige do pesquisador o papel de problematizador dos diferentes aspectos relativos a outros campos, como o pedagógico, o cultural, o social, entre outros.

Para Goodson (1997), o currículo foi criado como um dispositivo para dirigir e controlar o credenciamento dos professores e sua potencial liberdade nas salas de aula. A união entre prescrição e poder, ao longo dos anos, possibilitou que o currículo se tornasse um mecanismo de reprodução das relações de poder na sociedade.

Por ser construído levando em consideração as novas demandas para as quais as escolas estão sendo solicitadas, no currículo é possível encontrar a expressão de como a sociedade vem sendo estabelecida, e, com isso, que tipo de aluno procura-se formar para atender às suas necessidades.

Dessa maneira, como forma discursiva, o currículo possibilita a fabricação dos objetos de que fala (saberes, competências, sucesso) e dos sujeitos, o que torna relevante pensar no currículo juntamente com as relações e disputas de poder.

Desde sua gênese como macrotexto de política curricular até sua transformação em microtexto de sala de aula, passando por seus diversos avatares intermediários (guias, diretrizes, livros didáticos), vão ficando registrados no currículo os traços das disputas por predomínio cultural, das negociações em torno das representações dos diferentes grupos e das diferentes tradições culturais, das lutas entre, de 
um lado, saberes oficiais, dominantes e, de outro, saberes subordinados, relegados, desprezados. (SILVA, 2006, p. 22)

No contexto da cultura, o currículo é entendido como o conjunto de documentos, normas, regulamentos, princípios, conteúdos e práticas que orientam as ações educativas. Desta forma, é necessário que o currículo seja entendido por meio dos contextos históricos em que ele se encontra inserido, constituído, também, pelas práticas dos professores e da própria instituição.

O currículo não é um processo pronto e acabado, tampouco um resultado de evoluções contínuas. Sua história é marcada por grandes descontinuidades e rupturas, além de conflitos e lutas entre diferentes tradições e concepções sociais pelo o que deveria ser ensinado, como deveria ser ensinado e o porquê, em determinado momento histórico, daquilo ser ensinado.

Nessa perspectiva, o currículo deve ser visto não apenas como a expressão ou a representação ou o reflexo de interesses sociais determinados, mas também como produzindo identidades e subjetividades sociais determinadas. O currículo não apenas representa, ele faz. É preciso reconhecer que a inclusão ou exclusão no currículo tem conexões com a inclusão ou exclusão na sociedade. (GOODSON, 2001, p. 10)

Nas reformas educacionais, a atenção ao currículo é um dos elementos centrais, pois por meio dele é possível se depreenderem lutas em torno de diferentes significados sobre processos de formação que se dão em contextos sociais, econômicos e políticos mais amplos. Nas instituições educativas, em especial nas escolares, a constituição do currículo, muitas vezes, foi marcada por mudanças no sentido de atender às necessidades sociais de uma determinada época. Nesse contexto, na história moderna do currículo escolar, a noção de disciplina surge como uma forma de controlar, ordenar os conhecimentos ensinados às pessoas e passados de geração para geração, não sendo mero reflexo da ciência pura a que ela corresponde, mas, também, estando ligada a forças e interesses sociais sobre aquele conhecimento em determinado período.

Segundo Goodson, as disciplinas escolares são resultados de construções históricas e, portanto, sociais e políticas; são amálgamas imutáveis de subgrupos e tradições. Nessa perspectiva, a formação curricular não deve ser vista como independente do tempo social e histórico, mas como uma construção que leva em conta, além de outras dimensões, os conflitos entre as diferentes disciplinas na busca por status, recursos e territórios, conseguidos, na maioria das vezes, por meio da construção de um perfil acadêmico para cada campo disciplinar.

Nos últimos trinta anos, as discussões em torno da crise educacional e das reformas educativas têm colocado, ao campo da pesquisa, a busca de novos referencias teóricos que buscam interpretar de maneira menos homogeneizante o universo da escola. Nesse sentido, outros olhares vêm sendo estabelecidos perante as práticas escolares, por intermédio da valorização das ações cotidianas, dos profissionais que dela fazem parte, de suas trajetórias de vida, além das questões de raça, gênero e diferenças culturais. 
A emergência desse debate na década de 1970 impulsionou a crescente pesquisa acerca da cultura escolar, categoria de análise que passa a ganhar destaque nos anos de 1980, mas que se fortalece mesmo nos anos de 1990, apresentando, atualmente, diferentes tendências investigativas.

No que tange a historiografia da educação, há mais ou menos dez anos, a cultura escolar, enquanto categoria de análise, vem ganhando força e visibilidade nas pesquisas. Dentre as concepções mais utilizadas, destacamos autores como: Dominique Julia (2001), André Chervel (1990), Jean-Claude Forquin (1993), Agustín Escolano Benito (1999) e António Vinão Frago (1995).

Para Julia (2001), o estudo da cultura escolar permite uma investigação das práticas escolares como possibilidade de entender o funcionamento interno da escola, ou seja, de abrir e desvendar a "caixa-preta", metáfora muitas vezes utilizada por ele como valor de argumentação. Segundo o autor, além das normas e finalidades, a cultura escolar constitui-se, também, das práticas cotidianas quase imperceptíveis, nas quais podemos encontrar inventividades criadas pelos seus praticantes. Sendo assim, podemos pensar que a cultura escolar incorpora, também, os espaços, tempos e a materialidade da escola, podendo ser entendida como constituída por diversos tipos de manifestação cotidiana.

Para Vinão Frago, cada instituição escolar possui uma singularidade e, portanto, uma cultura. Por acreditar que há tantas culturas escolares quanto instituições de ensino, o autor prefere a acepção "culturas escolares".

Não existem duas escolas, colégios, institutos de ensino secundário, universidades ou faculdades exatamente iguais, ainda que se possa estabelecer semelhanças entre elas. As diferenças crescem quando comparamos as culturas de instituições que pertencem a distintos níveis educativos. (VINÃO FRAGO, 2001, p. 33)

Utilizar a cultura escolar como objeto de estudo pressupõe um olhar atento para as práticas escolares e as ações dos indivíduos enquanto consumidores ativos de propostas curriculares, de projetos oficiais, de espaços físicos, que astutamente estabelecem algumas relações e ressignificam outras. A sensibilidade para perceber as permanências e mudanças permite reconhecer o interior da escola como local permeado por conflitos e reconstruções constantes. Para Certeau, a noção de consumidores ativos passa pela assunção de que o cotidiano é lugar de invenção, e que as estratégias impostas pela ordem instituída (como a Igreja, a escola ou o poder jurídico) são sempre consumidas ou praticadas pelo homem ordinário, de forma astuta, portanto ativa. Daí vem a expressão consumidores ativos (CERTEAU, 1994).

Voltando às práticas escolares, é importante considerar que elas não podem ser vistas como desligadas das condições materiais para suas efetivações, uma vez que objetos e espaços, individuais ou coletivos, trazem as marcas da sua modelação. É preciso reconhecer que o uso e permanência de determinados materiais e lugares, o apagamento de alguns e o aparecimento de outros, nos permitem compreender as inventividades, muitas vezes imperceptíveis, dos praticantes desse cotidiano. 
O trabalho com a materialidade da escola tem permitido rastrear práticas, processos e relações constituintes dessa modalidade social, a escola, tal como a vimos seguindo: como prática cultural, que se constitui na intersecção de outras práticas culturais de nossa sociedade. (MENEZES, 2005, p. 13)

A cultura escolar e a organização do seu espaço físico são importantes objetos de análise quando pensamos em relações de poder, tanto de dominação como de resistência. É possível perceber, com o apagamento e movimentação de determinados espaços físicos e materiais, a importância que vem sendo dada a determinada disciplina escolar por seus praticantes, num movimento circular com as reformas curriculares.

\section{As políticas curriculares e a disciplina escolar Química}

No que se refere ao ensino de Química no Brasil, Chassot traz grandes contribuições para a compreensão da constituição sócio-histórica dessa disciplina, apontando registros oriundos do século XIX. Segundo Chassot, o primeiro decreto oficial que se refere ao ensino de Química no Brasil é de 6 de julho de 1810, com a criação de uma cadeira de Química na Real Academia Militar. Citando uma Carta de Lei de 4 de Dezembro do mesmo ano, ele nos mostra:

No quinto ano haverá dois lentes. O primeiro ensinará tática e estratégia; o segundo, ensinará Química, dará todos os métodos para o conhecimento das minas, servindo-se das obras de Lavoisier, Vanderquelin, Jouveroi, Lagrange e Chaptal para formar seu compêndio, onde fará toda sua aplicação às artes e a utilidade que dela derivam. (PM-02, p. 51 apud CHASSOT, 1996, p. 137)

Indo para o cenário do início do século XX, em 1918, com a criação do Instituto de Química no Rio de Janeiro, inicia-se a formação de profissionais para o trabalho nas indústrias Químicas recém-instaladas no país. No mesmo ano, é criado o curso de Química na Escola Politécnica de São Paulo e a pesquisa científica introduzida nesses centros de formação. A primeira instituição criada com a finalidade de formar químicos preparados para a pesquisa científica foi o Departamento de Química da Faculdade de Filosofia, Ciências e Letras da Universidade de São Paulo, em 1934 (MATHIAS, 1979).

Mesmo aparecendo nas grades curriculares das legislações educacionais brasileiras antes de 1925, é somente em 1931, com a Reforma Francisco Campos, que a disciplina escolar Química passa a ser ministrada de forma regular no currículo do Ensino Secundário no Brasil. Documentos da época apontam como objetivos para o ensino da Química: a formação do raciocínio lógico, a tarefa de despertar o interesse científico nos estudantes, como, também, enfatizar suas relações com a vida cotidiana (PETRUCCI-ROSA; TOSTA, 2005). 
A ambivalência entre o científico e o cotidiano, tão presente no currículo da disciplina escolar Química, foi se desfazendo nos anos 1970, período em que se percebe que a mesma passa a ser vista, mais acentuadamente, com um caráter científico, sobretudo pela criação do ensino técnico profissionalizante.

Nas últimas décadas, a implementação de propostas curriculares surge impulsionada por demandas específicas colocadas à articulação da educação com o contexto socioeconômico mundial. A disciplina Química, como todas as outras, passa a sofrer mudanças, as quais procuraremos enfatizar por meio de uma breve análise das últimas propostas curriculares para o Ensino Médio.

No Brasil, mais especificamente a partir da metade da década de 1990, documentos foram produzidos para promover mudanças curriculares tanto na Educação Básica como na Superior. No âmbito do Ensino Médio, os Parâmetros Curriculares Nacionais (PCNEM 1999) e as Orientações Curriculares Nacionais (OCNEM - 2006) representam as referências mais importantes produzidas nesse contexto.

Essas propostas curriculares trazem, dentre outras ideias, os conceitos de competências, habilidades, interdisciplinaridade e contextualização como noções didático-metodológicas capazes de organizar o ensino e de formar cidadãos aptos para as demandas exigidas na contemporaneidade, como: criticidade, flexibilidade, versatilidade, entre outras.

Tais noções estão muito relacionadas e articuladas às necessidades do mundo da produção atual. No que diz respeito ao conceito de competência, Oliveira (1999) salienta sua relação com um tipo de conhecimento prático, ligado à lógica capitalista. Segundo ele:

[...] o capital, ao utilizar o conceito de competência abstrai o desempenho de uma dada profissão das relações de conflito e incorpora, apenas, as dimensões subjetivas diretamente relacionadas ao comportamento que o trabalhador deve mostrar ao desenvolver uma atividade [...] o saber, em todas dimensões, fazer, ser, aprender, etc começam e terminam onde o capital determina. (OLIVEIRA, 1999, p. 58)

No que se refere, ainda, às noções de contextualização e interdisciplinaridade, elas parecem ainda ser consideradas como eixos didático-metodológicos possíveis para a organização do ensino, como nos aponta o documento:

Nesse contexto, é fundamental que as escolas, ao manterem a organização disciplinar, pensem em organizações curriculares que possibilitem o diálogo entre os professores das disciplinas da área de Ciências da Natureza e Matemática, na construção de propostas pedagógicas que busquem a contextualização interdisciplinar dos conhecimentos dessa área. O que se precisa é instituírem os necessários espaços interativos de planejamento e acompanhamento coletivo da ação pedagógica, de acordo com um ensino com característica contextual e interdisciplinar, ou seja, instituírem os coletivos organizados, como foi proposto nos PCNEM e PCN+. (BRASIL, 2006, p. 105) 
A principal diferença entre esses documentos encontra-se nos seus enfoques. Enquanto os PCNEM colocam como pilares da construção do currículo os princípios gerais de competências, interdisciplinaridade, contextualização, aos quais as disciplinas se subordinam e em torno dos quais elas se organizam, o foco das OCNEM volta-se para o trabalho com as disciplinas, consideradas como conhecimentos científicos que colaboram para a construção do conhecimento escolar.

No que se refere à contextualização do conhecimento, na visão dos autores das propostas curriculares, essa noção busca proporcionar um ensino com base no diálogo entre os conhecimentos pessoal, social e cultural, deslocando os alunos da posição de espectadores passivos. Segundo o próprio documento, “contextualizar o conteúdo que ser quer aprendido significa, em primeiro lugar, assumir que todo conhecimento envolve uma relação entre sujeito e objeto [...]" (BRASIL, 1999, p. 91).

Além da contextualização, defende-se, nos documentos, a interdisciplinaridade, entendida como a articulação entre as disciplinas em atividades e/ou projetos, partindo do princípio de que todo conhecimento mantém diálogo com outros campos, o que pode possibilitar a criação de condições mais efetivas de aprendizagem.

A proposta interdisciplinar de um currículo mais integrado para o Ensino Médio buscou novas formas de relacionamento e integração entre as diferentes disciplinas, sem a pretensão de se criar novas ou de se desfazer das existentes. Isso pode ser verificado pela forma como os documentos foram elaborados, uma vez que cada uma delas constituiu um documento exclusivo, bem definido e demarcado, com demandas próprias de competências e habilidades.

No que se refere aos documentos relacionados à disciplina Química, é possível visualizar, nos mesmos, a busca por um ensino que rompa com a simples memorização de fórmulas e fragmentos desligados da realidade dos alunos, ou seja, um conhecimento acadêmico fragmentado.

Seu ensino passa a ser desejado e estimulado por meio da relação com outras disciplinas e, também, por intermédio da contextualização do ensino, buscando, no cotidiano dos alunos, exemplos que tornem o aprendizado mais significativo, aumentando a compreensão que eles têm do mundo em que vivem, tornando-os mais críticos, capazes de compreender, argumentar e agir frente a diversas informações.

Dentro dessas perspectivas, defende-se a necessidade de se trabalhar o conhecimento científico e, com isso, a disciplina escolar Química, como dinâmica e mutável:

A Química pode ser um instrumento da formação humana que amplia os horizontes culturais e a autonomia no exercício da cidadania, se o conhecimento químico for promovido como um dos meios de interpretar o mundo e intervir na realidade, se for apresentado como ciência, com seus conceitos, métodos e linguagens próprios, e como construção histórica, relacionada ao desenvolvimento tecnológico e aos muitos aspectos da vida em sociedade. (BRASIL, 2002, p. 87)

Aliado ao ensino interdisciplinar e contextualizado, a presença das aulas laboratoriais, segundo os PCNEM, torna-se potencialmente importante por meio de demonstrações e 
experimentos que permitam discussões coletivas, construção de conceitos e desenvolvimento de competências e habilidades (BRASIL, 1999, p. 124).

No entanto, o próprio documento salienta que a experimentação feita na escola, com função pedagógica, difere da conduzida pelos cientistas; e, além disso, que a experimentação por si só, sem um aparato teórico feito pelo professor, não pode solucionar problemas de ensino-aprendizagem em Química.

Segundo as OCNEM, cabe ao professor o papel de desfazer a visão do laboratório enquanto espaço mágico ou de descoberta da verdade, e de construir, no aluno, a compreensão de que uma teoria é sempre criação e construção humana, e, por isso, dinâmica e provisória. $\mathrm{Na}$ circularidade produzida entre políticas públicas e práticas curriculares, escolas planejam, concebem e vivenciam suas culturas influenciadas pelos textos oficiais, fazendo recontextualizações e oferecendo formas de resistência e produção.

Tais recontextualizações e movimentos circulares não são "defeitos do sistema”. Há uma série de ressignificações que ocorrem no processo. Assim, os Parâmetros Curriculares Nacionais para Ensino Médio (1999/2000) ou as Orientações Curriculares Nacionais para o Ensino Médio (2004/2006), ou qualquer outra proposta, podem ser entendidos de acordo com as características de determinada instituição e da importância das disciplinas escolares para a comunidade educativa envolvida.

Nessa perspectiva, pode-se relacionar a leitura dos documentos das propostas educacionais por parte dos professores e gestores com a metáfora do apartamento alugado de Certeau (1994), onda cada leitor “torna o texto habitável, à maneira de um apartamento alugado. Ela transforma a propriedade do outro em lugar tomado de empréstimo, por alguns instantes, por um passante" (CERTEAU, 1994, p. 49).

Muito embora considere importante uma certa delimitação no espectro de significação dos textos, acreditamos que há possibilidade de múltiplas leituras para as propostas curriculares. Nesse sentido, é necessário considerar a heterogeneidade das instituições educativas, sobretudo as grandes diferenças existentes em um país territorialmente tão grande e culturalmente heterogêneo como o Brasil. Ao se considerar a heterogeneidade da grande massa consumidora $^{3}$ de currículo, constituída por praticantes produtores de saberes e fazeres, nos parece importante, aqui, lembrar as palavras de Certeau (1994), ao sugerir uma possibilidade analítica, abordando a cultura como lugar produtor de significados.

Para que haja verdadeiramente cultura, não basta ser autor de práticas sociais; é preciso que essas práticas sociais tenham significado para aquele que as realiza, pois a cultura não consiste em receber, mas em realizar o ato pelo qual cada um marca aquilo que os outros lhe dão para viver e pensar (CERTEAU, 1995, p. 9-10).

Para Certeau (1995), a cultura deve ser analisada como as práticas das pessoas comuns, as maneiras de fazer que, muitas vezes, aparecem como resistências ou inércias em relação ao desenvolvimento da produção sociocultural. Ao se considerar discursos de praticantes do cotidiano escolar cruzados com aqueles presentes nos documentos relacionados com propostas educacionais pós anos 1990, acredita-se que uma rede de significados faça emergir a compreensão de um lugar para a Química dentro das instituições escolares estudadas. 
É importante considerar que esse consumo não é passivo, ou seja, não se pode perder de vista a relevância de se investigar como novas denominações dos espaços escolares significam processos de engendramento de táticas de sobrevivência perante as estratégias produzidas pelas políticas curriculares. Segundo Certeau (1994):

Essas táticas manifestam igualmente a que ponto a inteligência é indissociável dos combates e dos prazeres cotidianos que articula, ao passo que as estratégias escondem sob cálculos objetivos a sua relação com o poder que os sustenta, guardado pelo lugar próprio ou pela instituição. (p. 47)

Não necessariamente as táticas precisam da existência de estratégias para serem desenvolvidas, porém, na maioria das vezes, essas táticas astutamente ocorrem frente a estratégias às quais, microfisicamente, passamos a ser submetidos. A estratégia encontra-se relacionada com a presença de um lugar próprio, um lugar de poder. Diferentemente, a tática é a ação calculada por meio da ausência de um próprio. Dessa forma, "a tática não tem por lugar senão o do outro. E por isso deve jogar com o terreno que lhe é imposto tal como o organiza a lei de uma força estranha... Em suma, a tática é a arte do fraco" (CERTEAU, 1994, p. 100-101).

As noções de tática e estratégia propostas por Certeau não devem ser entendidas e utilizadas como conceitos binários que exprimam ideia de oposição, mas como noções que ganham sentido quando constituídas na relação.

\section{O caso da Escola Distante}

Pretendemos, neste artigo, mostrar parte de um trabalho desenvolvido em nível de mestrado, realizado em duas escolas da rede pública da cidade de Campinas - SP, e que teve por objetivo investigar a reconfiguração do lugar da disciplina escolar Química no cotidiano dessas duas instituições.

Tentaremos explorar, neste artigo, como as ideias implementadas pelas propostas curriculares pós anos 1990 influenciaram em mudanças no espaço físico escolar, mais especificamente no que diz respeito aos possíveis lugares para a disciplina escolar Química dentro de uma dessas instituições de ensino, ficticiamente denominada de Escola Distante.

A busca pelo lugar da Química ocorreu no seu plano simbólico, por meio de objetos, que, dispostos fisicamente em determinados lugares no interior das escolas, trazem menções e significados de como tal disciplina vem sendo reinventada pelos praticantes do cotidiano.

É importante relembrar que, mesmo estando essa pesquisa inscrita no âmbito do ensino de Ciências, a literatura nesse campo não apresenta um conjunto numeroso de trabalhos que se apropriem do referencial teórico e das inspirações produzidas pelos escritos de Michel de Certeau. Nesse sentido, uma exceção a ser mencionada é a investigação desenvolvida por Santos e Mortimer (1999), que relaciona as noções de estratégia e tática certeaunianas com situações de ensino-aprendizagem em sala de aula.

Sendo assim, ao nos inserirmos no universo conceitual certeauniano, nos deparamos, também, com outros constructos teóricos que são extremamente inspiradores para a proble- 
mática da presente investigação, como, por exemplo, a noção de "lugar". Para Certeau (1994), o lugar é aquilo que dá a forma da existência social do sujeito. O sujeito aqui compreendido como a disciplina escolar Química, ocupa um lugar que molda sua existência dentro da instituição. Ainda para Certeau (1994), o lugar é também:

A ordem segundo a qual se distribuem elementos nas relações de coexistência. Aí se acha portanto excluída, para duas coisas, de ocuparem o mesmo lugar. Aí impera a lei do "próprio": os elementos considerados se acham uns ao lado dos outros, cada um situado num lugar "próprio" e distinto que define. Um lugar é portanto uma configuração instantânea de posições. Implica uma indicação de estabilidade. (CERTEAU, 1994, p. 201)

Esse lugar sempre se articula com a produção socioeconômica, política e cultural, ou seja, encontra-se submetido a imposições, ligado a privilégios e particularidades, e é em função desse lugar que, segundo Certeau (1994), os métodos são instaurados e que os documentos e as questões se organizam.

Instituição de ensino da rede pública da cidade de Campinas, a Escola Distante foi inaugurada, com seu nome atual, no ano de 1974, no mesmo local onde há muito tempo antes funcionava o antigo grupo escolar do bairro.

Atualmente, a escola possui cerca de 30 professores e atende cerca de 600 alunos, distribuídos em três turnos; sendo que, apenas nos períodos matutino e noturno, há salas de Ensino Médio, e, consequentemente, aulas de Química, e, para todas as turmas, a carga horária semanal dessa disciplina é de 2 horas.

Essa escola refere-se a um estabelecimento público de ensino próximo à periferia, em uma área de risco quanto à violência social, o que, muitas vezes, leva à suspensão de aulas por brigas entre gangues e toques de recolher feitos pelas mesmas, que são sempre atendidos, e nunca refutados, por professores e direção.

Muitas são as características e peculiaridades da Escola Distante, no entanto, nenhuma se destaca de forma tão exacerbada quanto os sucessivos acontecimentos relacionados ao seu laboratório de Química. Esse laboratório sempre foi tido como um dos melhores da região, possuindo muitos equipamentos, vidrarias, reagentes, como, também, espaço para a realização de experimentos.

No entanto, a partir de 2003, o laboratório, que já não vinha sendo muito utilizado, foi desfeito, e muitos dos seus equipamentos e materiais foram jogados ou realocados na montagem de uma outra sala no colégio, denominada sala de projetos.

A sala de projetos (também conhecida como oficina de artes) foi construída a partir da iniciativa da equipe gestora da própria escola, sem ônus para o Estado ou de outra instituição. Todos os materiais que ali existem, de certa forma, foram reciclados de outros locais, como salas de aulas, e, sobretudo, do próprio laboratório que lá funcionava.

Dentre o material coletado durante a pesquisa realizada nessa escola, parte dele foi constituído por entrevistas concedidas pelos professores de Química dessa instituição. Uma forma de construir essas entrevistas, buscando as particularidades e experiências dos professores atuantes nesse contexto, pode ser feita por meio do trabalho com as memórias dos 
mesmos. Inspiradas em Walter Benjamin, acreditamos que isso se torna possível ao se trabalhar com narrativas, compreendidas como uma alternativa de resistência e de ressignificação.

Para Benjamin, o trabalho com as narrativas tem por característica a possibilidade de trabalhar com aberturas e brechas, com a possibilidade de interlocuções com outros, sem procurar responder a todas as perguntas, muitas vezes até criando outras. Produzir narrativas não é só relatar, mas trazer as experiências no plural. "A experiência que passa de pessoa a pessoa é a fonte a que recorrem todos os narradores. E, entre as narrativas escritas, as melhores são as que menos se distinguem das histórias orais, contadas pelos inúmeros narradores anônimos" (BENJAMIN, 1994, p. 198).

A abordagem metodológica da narrativa propicia o levantamento dos saberes da experiência pedagógica, à medida que os narradores ficam à vontade para contar suas histórias de vida profissional, tendo como referência, nesse caso, suas percepções a respeito da Química enquanto disciplina escolar.

A visão de cada sujeito entrevistado é uma entre muitas possíveis, dessa forma, não consideramos as entrevistas como materiais absolutos capazes de esgotar a temática. É necessário, também, considerar que, do ponto de vista metodológico, ao buscar recuperar a história desse lugar - laboratório que se transforma em sala de projetos - contamos com snapshots (PAIS, 1999) expressos em narrativas e registros realizados em diferentes tempos. Os snapshots podem ser entendidos, segundo Pais (1999), como retratos únicos e, por vezes, transitórios, como "uma sociologia feita de episódios, de fragmentos, de instantâneos" (p. 12).

Para compor o material empírico da pesquisa, foram desenvolvidos procedimentos de construção de dados com abordagem etnográfica (ANDRÉ, 1978; ROCKWELL, 1986) e escuta de narrativas. Para isso, foi elaborado um extenso diário de campo, fruto de observação de, aproximadamente, dois anos imersa no cotidiano escolar, incluindo registros fotográficos.

Apresentamos, a seguir, excertos de narrativas de Olga e Gabriel, professores de Química efetivos da Escola Distante. Olga é bacharel e licenciada em Química, atualmente professora aposentada e lecionou durante 16 anos na Escola Distante (1994-2009). Gabriel também é bacharel e licenciado em Química. Ele trabalha na indústria há 26 anos e leciona há 21 anos, sendo 13 deles na Escola Distante (1997-2009). Além disso, para compor o material empírico, trazemos um fragmento do diário de campo.

\section{OLGA}

A gente utilizava muito o laboratório para ensinar. A gente tinha um grande laboratório de ciências e Quimica nessa escola, invejado por muitas outras escolas. Lembro das feiras de ciências que a gente fazia. O laboratório de Quimica era a sala mais visitada no colégio por alunos e pais. Posso dizer que nunca vi um laboratório tão bom e grande como o que tinha aqui em outra escola. Não faltavam vidrarias, reagentes e os professores naquela época, inclusive eu, a gente adorava levar os alunos para as aulas no laboratório.

Sei que perto de 2000, lembro que começou a se falar muito sobre trabalho interdisciplinar, também sobre cotidiano; trazer o cotidiano para a sala de aula. A cada ano nós éramos avisados sobre mudanças ou sobre trabalhos temáticos... Com os outros professores eu não sei, mas eu particularmente comecei a não ter tempo para levar os alunos para o laboratório. O tempo que tinha, eu usava para faz̧er os trabalhos com as outras disciplinas, que eram propostos pela coordenação, como o projeto "Água". 
Teve uma época que a gente começou a discutir a importancia do laboratório na escola, porque muitos professores e a direção reclamavam da quantidade de lixo que ele produzia e a necessidade de termos uma sala para colocar os projetos da escola.

Não me lembro bem ao certo quando. Talvez. em 2003, foi feita uma sala de projetos, ao lado do laboratório, utilizando muitos materiais dele, como bancada, vidraria para guardar tintas e o laboratório foi completamente abandonado. Hoje ele se tornou a tão sonhada sala de projetos deixando como lembrança da Química só a capela e as pias.

Figura 1. Capela do laboratório (sala de projetos) da Escola Distante

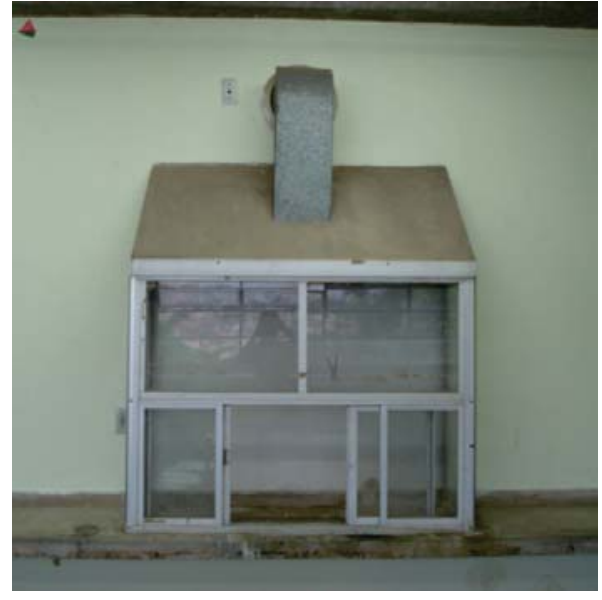

Fonte: Fotografia tirada pelas pesquisadoras.

Figura 2. Sala de projetos

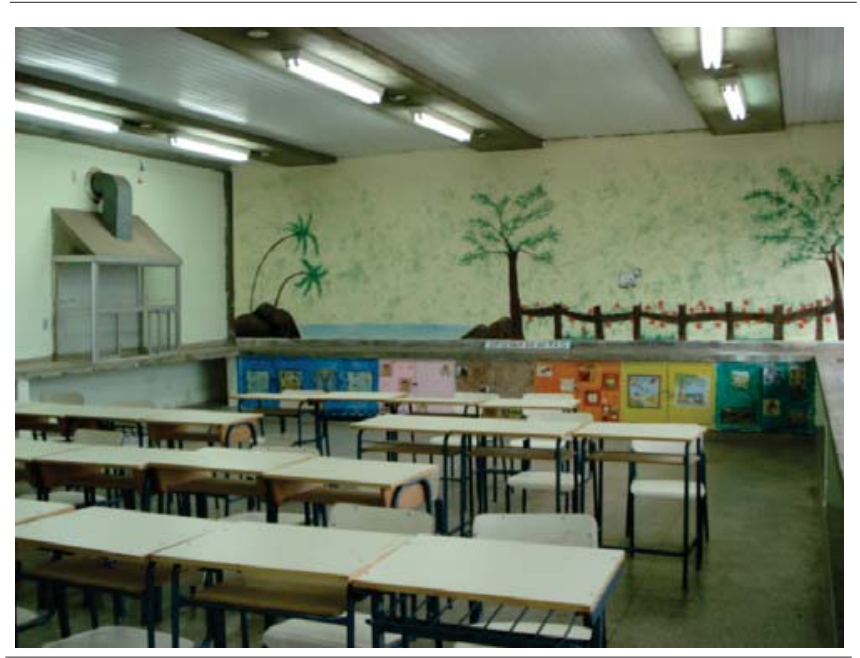

Fonte: Fotografia tirada pelas pesquisadoras. 


\section{GABRIEL}

Em 2000, lembro que me foram atribuidas aulas de manhã e a diretora quis que o laboratório fosse utilizado, mas não tinha mais nenhum material de Quimica nele. Os únicos reagentes que existiam estavam vencidos e a vidraria toda quebrada. Tudo isso estava jogado dentro da capela, misturado com teia de aranha e barata morta.

Lembro-me que numa certa manhã, eu e mais alguns professores fizemos uma limpeza junto com o pessoal da faxina e deixamos tudo guardado numa caixa para ser destinado para resíduo. Acredito que esse material nunca foi jogado fora, nem destinado para resíduo. Creio que esteja lá até hoje.

Sinceramente, não conheço essa sala de projetos. Lá é lugar para poucos...

Sei que a sala foi criada, acho que, em 2003, na intenção de guardar materiais feitos pelos alunos e ser um espaço físico destinado para a realização de trabalbos o que começou a acontecer quando nos chegaram as propostas de trabalhos temáticos e interdisciplinares.

É como eu já havia dito, não a conheço e não vejo motivos para utilizar essa sala. Primeiro, porque só alguns professores têm tempo para levar seus alunos lá, como a professora de Artes, de Geografia e de História e também porque não tem nada para en fazer lá. O que eu vou fazer numa sala de projetos que só tem cola, tinta e cartolina?

\section{DIÁRIO DE CAMPO}

Finalmente para muitos e infelizmente para poucos, talvez apenas para mim, o laboratório se transformou na tão sonhada sala de artes (mais conhecida entre alunos e professores como sala de projetos). Depois de tantos problemas e busca de soluções para os descartes, fiquei sabendo com a coordenadora, que eles, assim como as vidrarias, foram jogados numa caçamba de lixo, com os restos das obras que estão sendo feitas na escola. Nas palavras da coordenadora: "Aproveitamos a caçamba e jogamos os descartes lá. Ninguém queria ou conseguia dar um fim naquilo. Foi a única solução."

No momento que ouvi isso, sem exagerar, meu mundo caiu. Tudo o que havia aprendido, lido e estudado parecia não fazer sentido. Fiquei pensando como é que uma coordenadora podia ter coragem de falar isso. Jogar tudo no lixo, principalmente os descartes... Por muito tempo suas palavras ficaram ecoando em minha cabeça.

Fora a capela, pias e tomadas restantes, qualquer vestígio do antigo laboratório foi apagado. Agora temos uma sala de projetos bem diferente da anterior, que era em outra sala e utilizava os materiais do antigo laboratório.

A sala de projetos atual que fica no espaço ocupado pelo antigo laboratório é uma sala de aula normal. O que a diferencia das outras é que suas paredes foram pintadas, sendo que em uma delas encontra-se uma placa onde há escrito "oficina de artes", além dos armários, também pintados, onde são guardados os materiais dessa oficina.

Todo e qualquer vestígio de química foi apagado. Até mesmo os tubos de ensaio, minha última esperanç, nem que continuassem ali para guardar lantejoulas, foram jogados.

\section{Alguns indícios...}

As práticas cotidianas nos oferecem indícios que tornam possível a compreensão de uma gama de significados e relações de poder existentes nas instituições escolares. Na pesquisa aqui apresentada, essas práticas ajudaram a entender possíveis indícios de relações entre a 
reconfiguração dos lugares para a disciplina Química, no contexto da Escola Distante, com os discursos presentes nas propostas curriculares nacionais iniciadas após os anos 1990.

Professores, alunos e gestores, em todos os momentos, foram vistos e ouvidos como praticantes ordinários da vida cotidiana (CERTEAU, 1994), por transformarem e consumirem ativamente o currículo escolar, por reinventarem, ressignificarem e criarem, utilizando maneiras de faz̧er (CERTEAU, 1994), as estratégias estabelecidas por meio do uso de táticas.

Foi nas brechas criadas pelas próprias estratégias, que pude perceber ações e práticas dos professores como formas de questionamentos e modificações, como aberturas que possibilitaram invenções e exercício de poder durante a busca de espaço para sua disciplina. Como aponta Certeau (1994, p. 19), "sempre é bom recordar que não se deve tomar os outros por idiotas".

Segundo as narrativas de Olga e Gabriel, bem como os registros advindos do diário de campo, é possível constatar que a Química, que ocupava, simbolicamente, um lugar de mais destaque na cultura da Escola Distante, foi perdendo espaço por intermédio de mudanças constatadas no que diz respeito, sobretudo, ao laboratório. A exclusão do laboratório significou, para esses professores, uma mudança de importância desse espaço ao chegarem os trabalhos temáticos e interdisciplinares.

O laboratório, nessa instituição de ensino, deixa de ter importância e, materialmente, torna-se uma sala de projetos. Isso pode ter acontecido por meio de táticas, artes de fazer dos sujeitos dessa instituição diante das propostas curriculares que preconizam práticas de currículos integrados.

O escopo dessa pesquisa não está focalizado na compreensão e análise das abordagens experimentais no ensino de Química e suas potencialidades para aprendizagem. Assumem-se, por outro lado, as lutas simbólicas no contexto da cultura da escola e nas ações cotidianas, a partir das quais é possível depreender que a substituição de um lugar/sala chamado laboratório, por um espaço denominado sala de projetos, parece estar relacionada à assunção de tentativas de práticas curriculares integradas do ponto de vista das disciplinas escolares. Da mesma forma, objetos tradicionalmente relacionados com a disciplina escolar Química, tais como estoques de vidrarias e reagentes, ao caírem em desuso, são descartados sem os cuidados necessários.

Por outro lado, podemos pensar que as mudanças geradas por esses usos dos documentos curriculares foram também possibilitadas pelas questões já presentes no cotidiano dessa escola, em relação ao laboratório: dificuldade de lidar com descarte de resíduos tóxicos provenientes das atividades experimentais do ensino.

Como uma forma de tática, a equipe gestora da escola pode ter se apropriado de um princípio presente no PCNEM - a integração ou interdisciplinaridade - para se "livrar" do laboratório e criar um espaço que poderia ser utilizado por todas as áreas curriculares.

Nesse mesmo contexto, a forma indiferente com que Olga se refere à sala de projetos pode remeter também à ideia de que o lugar ocupado por uma disciplina depende da relação entre o professor e a direção.

Os documentos produzidos nos movimentos de reformulações educacionais pós anos 1990, mais especificamente os Parâmetros Curriculares Nacionais para o Ensino Médio (PCNEM) de 1999 e as Orientações Curriculares Nacionais para o Ensino Médio (OCNEM) de 2006, defendem o estabelecimento de um ensino de Química mais relacionado a uma 
formação interdisciplinar e contextualizada, que possibilite, aos alunos, a visão da Química como disciplina presente nas ações e acontecimentos do dia a dia, e não mais por meio do conhecimento abstrato, fragmentado e acadêmico/científico visto como verdade absoluta.

Isso nos leva a perceber que o discurso de integração e interdisciplinaridade assume diferentes ressignificações, podendo se desdobrar em diferentes ações, desde o ensinado em sala de aula até a reorganização do espaço escolar.

É possível observar, nas falas dos professores, que a extinção de um possível lugar para a Química é também resultado de modificações e práticas impulsionadas pelos discursos presentes nos últimos documentos curriculares nacionais, que transformou esses antigos lugares em espaços, definido, segundo Certeau (1994) como lugar praticado.

Inicialmente, entre espaço e lugar, coloco uma distinção que delimitará um campo. Um lugar é a ordem (seja qual for) segundo a qual se distribuem elementos nas relações de coexistência. Aí se acha portanto excluída a possibilidade, para duas coisas, de ocuparem o mesmo lugar. Aí impera a lei do "próprio": os elementos considerados se acham uns ao lado dos outros, cada um situado num lugar "próprio" e distinto que define. Um lugar é portanto uma configuração instantânea de posições. Implica uma indicação de estabilidade. Existe espaço sempre que se tomam em conta vetores de direção, quantidades de velocidade e a variável tempo. O espaço é um cruzamento de móveis. É de certo modo animado pelo conjunto dos movimentos que aí se desdobram. Espaço é o efeito produzido pelas operações que o orientam, o circunstanciam, o temporalizam e o levam a funcionar em unidade polivalente de programas conflituais ou de proximidades contratuais... Diversamente do lugar, não tem portanto nem a univocidade nem a estabilidade de um “próprio". Em suma, o espaço é um lugar praticado. (CERTEAU, 1994, p. 201-202)

Inseparáveis do contexto, as táticas exercidas pelos praticantes do cotidiano, operações de usos que se tornam possíveis nas lacunas, brechas das estratégias, só podem ocorrer a partir de um lugar próprio, onde os elementos que o constitui estão organizados de forma estável. O lugar representa uma vitória sobre o tempo, uma ação que organiza seus elementos sem considerar seus movimentos.

Assim, o laboratório, um lugar geograficamente composto por reagentes, bancadas, vidrarias, estufa, tabela periódica, é transformado em espaço por alunos e professores em suas práticas escolares, denominado sala de projetos. O exercício desse espaço, assim como as práticas que nele ocorrem, encontra-se entrelaçado a relações de poder, seja para a destruição ou manutenção desse espaço físico.

Dessa forma, espaços e lugares parecem ser concebidos num processo circular de organização espacial, ocasionado pela criação e exercícios de estratégias e táticas, onde espaços são transformados em lugares e vice-versa (JOSGRILBERG, 2004).

$\mathrm{Na}$ pesquisa feita dentro dessas instituições de ensino, ao procurar um lugar para a Química, encontramos um espaço (lugar praticado) que colocou a Química no seu lugar morto 
(CERTEAU, 1994), seu “estar aî" mesmo que no esquecimento. Dessa forma, além da Química ter perdido seu lugar, ela ficou também sem espaço, uma vez que esse último foi constituído e transformado para ser utilizado em contextos muito diversos e distantes dessa disciplina e de sua utilização original.

Num exame das práticas do dia-a-dia que articulam essa experiência, a oposição entre "lugar" e "espaço" há de remeter sobretudo, nos relatos, a duas espécies de determinações: uma por objetos que seriam no fim das contas reduzíveis ao estar-aí de um morto, lei de um "lugar" (da pedra ao cadáver, um corpo inerte parece sempre, no Ocidente, fundar um lugar e dele fazer a figura de um túmulo); a outra, por operações que, atribuídas a uma pedra, a uma árvore ou a um ser humano, especificam "espaços" pelas ações de sujeitos históricos (parece que um movimento sempre condiciona a produção de um espaço e o associa a uma história). (CERTEAU, 1994, p. 203)

O cotidiano escolar, assim como a cultura de uma determinada escola, permite visualizar como as estratégias e ações táticas constituem lugares para uma dada disciplina que vão aparecendo ou desaparecendo de acordo com as necessidades e discursos que passam a circular nesse cotidiano.

Com a pesquisa apresentada neste artigo, é possível concluir que os inúmeros movimentos que ocorrem nas culturas das escolas tornam-se essenciais para a investigação de ações que ali são desenvolvidas, como, por exemplo, as ações táticas de praticantes desse contexto perante os discursos implementados pelas propostas curriculares num cotidiano que, embora pareça ser sempre repetição, encontra-se permeado por criações, usos ativos e recriações.

Há mais de uma década da publicação dos primeiros documentos curriculares provenientes de políticas nacionais (BRASIL, 1999; BRASIL, 2006), pode-se concluir que as instituições escolares estão num movimento pleno de contradições, apagamentos e reposicionamentos, sobretudo, no que se refere ao dilema científico/cotidiano, tão presente nas ações curriculares provenientes da presença de disciplinas de origem científica.

Como analisado anteriormente, segundo Lopes e Macedo (2005), as disciplinas escolares precisam ser entendidas como: tecnologias de organização curricular, produtos de recontextualizações de discursos, híbridos de discursos curriculares e, sobretudo, construções sócio-históricas.

Nessa perspectiva, podemos pensar que as atuais demandas para um mundo do trabalho, baseadas em noções como competências, habilidades, versatilidade e flexibilização, relacionadas ao momento histórico educacional brasileiro contemporâneo, podem ser um dos fatores que esteja produzindo efeitos na constituição da disciplina escolar Química no cotidiano da escola, o que permite explicar a reconfiguração de seu lugar dentro das instituições de ensino. 


\section{Agradecimentos}

Este artigo é resultado de uma pesquisa, em nível de mestrado, que foi desenvolvida com apoio financeiro da CAPES.

\section{Referências}

ANDRÉ, M. E. D. A. A abordagem etnográfica: uma nova perspectiva na avaliação educacional.

Tecnologia Educacional, v. 24, p. 9-12, 1978.

BENJAMIN, W. Obras escolhidas I: magia e técnica, arte e política - ensaios sobre literatura e história da cultura. 7. ed. São Paulo: Brasiliense, 1994.

BRASIL. Ministério da Educação. Secretaria de Educação Média e Tecnológica. Parâmetros curriculares nacionais: ensino médio. Brasília: Ministério da Educação, 1999.

. Ministério da Educação, Secretaria de Educação Média e Tecnológica. PCN + Ensino Médio:

Orientações educacionais complementares aos Parâmetros Curriculares Nacionais - Ciências da Natureza, Matemática e suas Tecnologias. Brasília: Ministério da Educação, 2002.

. Ministério da Educação, Secretaria de Educação Básica, Departamento de Políticas de Ensino Médio. Orientações Curriculares do Ensino Médio. Brasília: Ministério da Educação. v. 2, 2006.

CERTEAU, M. A Invenção do Cotidiano. Artes de Fazer. Petrópolis: Editora Vozes, 1994.

A cultura no plural. Campinas, SP: Papirus, 1995.

CHASSOT, A. I. Uma história da educação química brasileira: Sobre seu início discutível apenas a partir dos conquistadores. Epistéme, Porto Alegre, vol. 1, n. 2, p. 129-146, 1996.

CHERVEL, A. História das disciplinas escolares: reflexões sobre um campo de pesquisa. Revista Teoria e Educação, Porto Alegre, v. 2, p. 177-229, 1990.

ESCOLANO BENITO, A. Los professores en la historia. In: MAGALHÃES, J.; ESCOLANO BENITO, A. (Org.). Os professores na história. Porto: Sociedade Portuguesa de Ciências da Educação, 1999. p. 15-27.

FORQUIN, J. Escola e cultura: as bases sociais e epistemológicas do conhecimento escolar. Porto Alegre: Artes Médicas, 1993.

GOODSON, I. F. A construção social do currículo. Lisboa: EDUCA, 1997.

Currículo: teoria e história. 4. ed. São Paulo: Editora Vozes, 2001.

JOSGRILBERG, F. B. Michel de Certeau e mídia: táticas subvertendo lugares ou lugares organizando táticas? Revista Comunicação e Sociedade, n. 37, p. 13-24, 2004.

JULIA, D. A. Cultura Escolar como Objeto Histórico. Revista Brasileira de História da Educação, n. 1, p. 9-44, 2001.

LOPES, A. R. C.; MACEDO, E. O pensamento curricular no Brasil. In: (Org.). Currículo: debates contemporâneos. 2. ed. São Paulo: Cortez, 2005. p. 13-54.

MATHIAS, S. Evolução da Química no Brasil. In: FERRI, M. G.; MOTOYAMA, S. (Org.). História das ciências no Brasil. São Paulo: Edusp, 1979. 
MENEZES, M. C. A escola e sua materialidade: o desafio do trabalho e a necessidade da interlocução. Revista Pro-Posições, Campinas, v. 16, n. 1(46), p. 13-18, 2005.

OLIVEIRA, R. Empregabilidade e competência: conceitos novos sustentando velhos interesses. Revista Trabalho e Educação, Belo Horizonte, n. 5, 1999.

PAIS, J. M. Traços e riscos de vida. Uma Abordagem Qualitativa a Modos de Vida Juvenis. Porto: Ambar, 1999.

PETRUCCI-ROSA, M. I. P.; TOSTA, A. H. O lugar da Química na escola - movimentos constitutivos da disciplina no cotidiano escolar. Ciência \& Educação, Bauru, v. 11, n. 2, p. 253-262, 2005.

ROCKWELL, E. Etnografia e Teoria na Pesquisa Educacional. In: EZPELETA, J.; ROCKWELL, E. (Org.). Pesquisa participante. São Paulo: Cortez, 1986.

SANTOS, F. M. T.; MORTIMER, E. F. Táticas de Resistência e Aulas de Química. Química Nova na Escola, São Paulo, n. 10, p. 38-42, 1999.

SILVA, T. T. O currículo como fetiche: a poética e a política do texto curricular. Belo Horizonte: Autêntica, 2006.

VINÃO FRAGO, A. Historia de la educación e historia cultural. Revista Brasileira de Educação, São Paulo, n.0, p. 63-82, 1995.

. Fracasan las reformas educativas? La respuesta de un historiador. In: SOCIEDADE

BRASILEIRA DE HISTÓRIA DA EDUCAÇÃO (Org.). Educação no Brasil: história e historiografia. Campinas: Autores Associados: SBHE, 2001. p. 21-52.

Artigo recebido em 26/11/13. Aceito em 04/03/14. 